\title{
AVALIAÇÃO DA COMPOSIÇÃO QUÍMICA EM QUEIJO PARMESÃO COMERCIALIZADO EM PARANAVAÍ - PARANÁ
}

\author{
Chemical composition in Parmesan cheese marketed \\ in Paranavaí - Paraná
}

\author{
Fernanda Duarte Gomes ${ }^{1}$, Aline Alves ${ }^{l}$, Tatiana Colombo Pimentel ${ }^{1 *}$ \\ Suellen Jensen Klososki ${ }^{I}$
}

\begin{abstract}
RESUMO
O queijo Parmesão ralado está entre os mais consumidos do país e também entre os mais fraudados, visto que a fragmentação facilita a incorporação de diversos adulterantes. A legislação brasileira estabelece como parâmetros a ser avaliados em queijo ralado apenas o teor de umidade e o conteúdo de gordura no extrato seco (GES). No entanto, é importante analisar outros parâmetros, a fim de caracterizar os produtos comercializados no Brasil, pois a qualidade pode estar comprometida. O objetivo do presente trabalho foi analisar a composição química e a presença de amido em diferentes amostras de queijo parmesão ralado, comercializadas na cidade de Paranavaí, Paraná. Foram analisadas quinze amostras, sendo de três lotes diferentes de cinco marcas. A composição química (umidade, cinzas, carboidratos, proteínas e lipídios) diferiu de uma amostra para outra, no entanto, todas as amostras estavam em conformidade com a legislação brasileira considerando os conteúdos de umidade. Quanto ao teor de GES, 60\% das amostras apresentavam valores superiores aos estabelecidos pela legislação brasileira para queijo semigordo, como o queijo Parmesão ralado. Uma das amostras apresentou teor de carboidratos elevado, no entanto, não foi constatada a presença de amido pelo teste do lugol. Conclui-se que $60 \%$ dos queijos ralados comercializados na cidade de Paranavaí apresentam desconformidade com a legislação brasileira, pois tinham maior conteúdo de gordura no extrato seco do que o estabelecido.

Palavras-chave: queijo ralado; amido; legislação; qualidade; composição centesimal.
\end{abstract}

1 Instituto Federal do Paraná (IFPR), Campus Paranavaí, Rua José Felipe Tequinha, 1400, Jardim das Nações, 87703-536, Paranavaí, PR, Brasil. E-mail: tatiana.pimentel@ifpr.edu.br

* Autor para correspondência.

Recebido / Received: 09/12/2014

Aprovado / Approved: 12/02/2016 


\begin{abstract}
The grated Parmesan cheese is among the most consumed cheese in the country and also among the most fraudulent, since the fragmentation facilitates the incorporation of various adulterants. Brazilian law establishes as the parameters to be evaluated in grated cheese only the moisture content and the fat content in dry matter (GES). However, it is important to analyze other parameters, in order to characterize the products commercialized in Brazil, as quality can be compromised. The objective of this study was to analyze the chemical composition and presence of starch in different samples of grated Parmesan cheese, commercialized in the city of Paranavaí, Paraná. Fifteen samples were analyzed, being three different batches of five brands. The chemical composition (moisture, ash, carbohydrates, proteins and lipids) differed from one sample to another; however, all samples were in compliance with Brazilian legislation, considering the moisture content. For the GES content, $60 \%$ of the samples showed values higher than those established by Brazilian legislation for semi-fat cheese, such as grated Parmesan cheese. One sample showed a high carbohydrate content, however, starch was not detected by the lugol test. It is concluded that $60 \%$ of grated cheese commercialized in the city of Paranavaí present disagreement with Brazilian law, because they had higher fat content in the dry matter than the established.
\end{abstract}

Keywords: grated Parmesan cheese; starch; legislation; quality; composition.

\section{INTRODUÇÃO}

O queijo é um alimento de grande importância nos hábitos de consumo dos brasileiros devido a sua rica composição nutricional e participação histórica na cultura nacional. É um alimento produzido a partir do leite, contendo proteínas de alto valor biológico, cálcio, lipídeos, lactose e vitaminas lipossolúveis (OLIVEIRA et al., 2012).

O queijo parmesão é classificado como de baixa umidade, semigordo, de massa cozida, prensada e de longa maturação (de seis meses a dois anos). Possui consistência dura e textura compacta, granulosa, com crosta firme e lisa, cor ligeiramente amarelada e sabor levemente picante e salgado. Seu odor é suave e agradável, devendo ser armazenado em temperatura não superior a $18{ }^{\circ} \mathrm{C}$. É muito comercializado na forma ralada (BRASIL, 1997a, PERRY, 2004).

O queijo ralado pode ser definido como um produto obtido por esfarelamento ou ralagem da massa de uma ou até quatro variedades de queijos de baixa umidade aptos para o consumo humano. O produto classifica-se como desidratado ou não e/ou pela variedade de queijo utilizada, podendo ser elaborado com uma única variedade de queijo de baixa umidade ou com queijo de média umidade (BRASIL, 1997b).

A legislação brasileira estabelece limites apenas para umidade e gordura no extrato seco (GES) de queijos ralados. O queijo parmesão ralado e desidratado deve apresentar teor máximo de umidade de $20 \%$ e GES compatível com produtos semi-gordos (25-44,9\%) (BRASIL, 1996; BRASIL, 1997 a, b). Estudos indicam que estes limites são usualmente extrapolados (PIMENTEL et al., 2002; INMETRO, 2003; JUSTUS et al., 2011; OLIVEIRA et al., 2012; TROMBETE et al., 2012), o que torna importante o monitoramento sistemático dos produtos disponíveis no mercado.

Embora a umidade e o conteúdo de gordura sejam parâmetros importantes de avaliação da qualidade de queijos ralados, é 
essencial analisar outros parâmetros, a fim de caracterizar os produtos comercializados no Brasil e garantir qualidade àqueles oferecidos aos consumidores (JUSTUS et al., 2011). Portanto, este trabalho teve como objetivo analisar a composição química e avaliar a presença de amido em diferentes amostras de queijo parmesão ralado, comercializadas na Região de Paranavaí, Paraná.

\section{MATERIAL E MÉTODOS}

\section{Material}

Foi analisado um total de 15 amostras adquiridas no comércio local (Paranavaí, Paraná), sendo 3 unidades de lotes diferentes pertencentes a 5 marcas de queijo parmesão ralado. A seleção das marcas foi baseada em uma pesquisa nos mercados da cidade, avaliando-se a disponibilidade da marca e o quantitativo de vendas. As 5 marcas selecionadas foram encontradas em todos os mercados de porte médio da cidade e, segundo os estabelecimentos, eram aquelas que tinham maior porcentagem de vendas. Os queijos foram classificados, segundo a própria embalagem, como queijo ralado de baixa umidade. Todas as amostras apresentavam selo de Inspeção Federal (SIF) e estavam den- tro do prazo de validade estabelecido pelo fabricante.

\section{Análise de composição química}

A composição química foi determinada conforme metodologias propostas pelo Manual do Instituto Adolf Lutz (2008): umidade por gravimetria após dessecação em estufa a $105^{\circ} \mathrm{C}$, minerais (cinzas) por gravimetria após incineração em mufla a $550{ }^{\circ} \mathrm{C}$, proteína pelo método de micro-Kjeldahl, lipídios pelo método de Bligh-Dyer e carboidratos por diferença. A presença ou ausência de amido nas amostras foi realizada por meio de gotejamento de lugol.

\section{Análise estatística}

As diferentes marcas serão denominadas como amostras A, B, C, D e E. Utilizou-se o delineamento inteiramente casualizado com cinco amostras (marcas) de queijo ralado, em três lotes diferentes e três repetições. Nas análises de composição química os resultados foram submetidos à Análise de Variância (ANOVA) e teste de comparação de médias de Tukey $(\alpha=5 \%)$. As análises estatísticas foram realizadas usando o programa Statistical Analysis System (SAS) 9.1.3.

Tabela 1 - Composição química $(\mathrm{g} / 100 \mathrm{~g})$ de cinco marcas de queijo parmesão ralado comercializados em Paranavaí - PR*

\begin{tabular}{lccccc}
\hline Componente & $\mathrm{A}$ & $\mathrm{B}$ & $\mathrm{C}$ & $\mathrm{D}$ & $\mathrm{E}$ \\
\hline Umidade & $18,31 \pm 0,33^{\mathrm{a}}$ & $17,29 \pm 0,60^{\mathrm{ab}}$ & $15,58 \pm 0,14^{\mathrm{c}}$ & $16,27 \pm 0,46^{\mathrm{bc}}$ & $16,66 \pm 0,31^{\mathrm{abc}}$ \\
Cinzas & $9,16 \pm 0,3^{\mathrm{a}}$ & $7,59 \pm 0,95^{\mathrm{b}}$ & $8,60 \pm 0,67^{\mathrm{a}}$ & $7,04 \pm 0,55^{\mathrm{b}}$ & $6,09 \pm 0,59^{\mathrm{c}}$ \\
Proteínas & $31,84 \pm 0,83^{\mathrm{bc}}$ & $34,45 \pm 0,55^{\mathrm{b}}$ & $41,47 \pm 0,48^{\mathrm{a}}$ & $30,36 \pm 0,32^{\mathrm{c}}$ & $38,91 \pm 3,1^{\mathrm{a}}$ \\
Lipídeos & $38,88 \pm 0,99^{\mathrm{a}}$ & $41,61 \pm 2,03^{\mathrm{a}}$ & $33,28 \pm 0,33^{\mathrm{b}}$ & $30,53 \pm 2,71^{\mathrm{b}}$ & $40,72 \pm 0,31^{\mathrm{a}}$ \\
GES $* *^{*}$ & $47,50 \pm 1,08^{\mathrm{a}}$ & $50,31 \pm 2,74^{\mathrm{a}}$ & $39,43 \pm 0,33^{\mathrm{b}}$ & $36,48 \pm 3,44^{\mathrm{b}}$ & $48,85 \pm 0,20^{\mathrm{a}}$ \\
Carboidratos & $1,81^{\mathrm{b}}$ & $0^{\mathrm{c}}$ & $1,07^{\mathrm{b}}$ & $15,8^{\mathrm{a}}$ & $0^{\mathrm{c}}$ \\
\hline
\end{tabular}

* Valores médios para três amostras de cada marca.

** Letras iguais numa mesma linha indicam valores semelhantes pelo Teste de Tukey $(\alpha=5 \%)$.

*** Gordura no extrato seco. 


\section{RESULTADOS E DISCUSSÃO}

Na Tabela 1 estão apresentados os resultados de composição química dos queijos ralados avaliados.

Não foi detectada a presença de amido nas amostras de queijo ralado avaliadas neste estudo. A adição de amido em queijo ralado não é permitida pela legislação vigente (BRASIL, 1997b). No entanto, alguns produtores fazem esta adição durante a etapa de ralamento do queijo, pois o amido apresenta baixo custo e aumenta o rendimento do produto final (DUARTE et al., 2006).

A adição de amido não causa danos à saúde do consumidor, visto que este é utilizado como importante fonte de carboidratos na alimentação humana (DUARTE et al., 2006). No entanto, não faz parte da tecnologia de fabricação de queijos ralados e sua adição ocasiona alterações nos conteúdos finais dos demais componentes (proteínas, lipídios, cinzas), descaracterizando o produto (RIBEIRO et al., 2012). A ausência de amido significa que não houve essa prática fraudulenta na fabricação dos queijos ralados avaliados neste estudo, embora outros tipos de fraude possam existir e não tenham sido avaliados. Outros autores observaram, no entanto, a presença de amido em amostras de queijo ralado comercializadas em Ponta Grossa (RIBEIRO et al., 2012) e no Rio de Janeiro (ROMANO; AZEVEDO, 2005; DUARTE et al., 2006).

Quanto à umidade, a legislação brasileira preconiza um teor máximo de $20 \%$ para queijos ralados desidratados (BRASIL, 1997 a, b). Sendo assim, todas as amostras de queijo analisadas (A, B, C, D e E) atenderam à legislação vigente em relação ao teor de umidade.

Valores de umidade superiores aos preconizados pela legislação podem facilitar a multiplicação de microrganismos deteriorantes, diminuindo o tempo de vida útil dos produtos. Há ainda o risco de veiculação de microrganismos patogênicos, como $L$. monocytogenes, a qual se desenvolve em queijos cuja umidade seja superior a $20 \%$ (OLIVEIRA et al., 2012). Além disso, pode representar prejuízos ao consumidor, pois o mesmo está comprando um queijo com um teor superior de água e pagando o mesmo preço que seria pago por um com umidade adequada (INMETRO, 2003). Há ainda, comprometimento da concorrência justa entre fabricantes, por alguns estarem obtendo vantagens em seus produtos de maneira ilegal (TROMBETE et al., 2012). Níveis de umidade acima do limiar desejável foram relatados em outros estudos (PIMENTEL et al., 2002; RIBEIRO et al., 2012; OLIVEIRA et al., 2012; TROMBETE et al., 2012).

O conteúdo de cinzas variou entre $6,09 \%$ a $9,16 \%$, sendo maior nas amostras A e $\mathrm{C}$ e menor na amostra $\mathrm{E}$. As cinzas no queijo são representadas pelas substâncias salinas e materiais minerais presentes no leite e/ou adicionados durante a fabricação do queijo (PEREIRA et al., 2001). O sal adicionado durante a salga representa uma grande proporção das cinzas e, como a quantidade e a forma de adição diferem de uma indústria para outra, contribuem para as diferenças nos conteúdos de cinzas encontrados (JUSTUS et al., 2011). Os teores de cinzas encontrados no presente estudo estão de acordo com os relatados por outros autores (JUSTUS et al., 2011; RIBEIRO et al., 2012).

A quantidade de lipídios variou entre $30,53 \%$ a $41,61 \%$. Os teores mais baixos foram $30,53 \%$ e $33,28 \%$ para as amostras C e $\mathrm{D}$, respectivamente, e os mais altos foram nas amostras A $(38,88 \%), \mathrm{B}(41,61 \%)$ e $\mathrm{E}$ $(40,72 \%)$. A variação do teor de gordura em queijos pode estar relacionada com diversos fatores, como o teor de gordura inicial do leite, o momento de corte da coalhada e o tipo de pasteurização do leite (JUSTUS et al., 2011). Além disso, a raça do animal do qual o leite foi retirado, o estágio de lactação, a 
alimentação e a estação do ano podem alterar os níveis encontrados no leite (CARROLL, 2006).

A legislação brasileira preconiza que o teor de gordura no extrato seco para queijo Parmesão ralado deve ser compatível com os padrões estabelecidos para queijos semigordos (25-44,9\%) (BRASIL, 1996; BRASIL, 1997 a,b). Desta forma, 60\% das amostras de queijo analisadas no presente estudo apresentaram conteúdos de GES superiores aos limites permitidos, sendo classificadas como queijos gordos. RIBEIRO et al. (2012) e JUSTUS et al. (2011) observaram que 66,67 e $37,5 \%$ das amostras de queijo parmesão ralado de Ponta Grossa - PR e Sul de Minas, respectivamente, apresentavam GES compatível com queijos gordos, estando em desacordo com a legislação vigente.

Quanto ao conteúdo proteico, a legislação brasileira não estabelece padrões para o queijo parmesão ralado. O valor médio encontrado nas amostras para proteína total foi de 35,41\%, observando-se maiores teores nas amostras C $(41,47 \%)$ e E $(38,91 \%)$ e menores teores nas amostras A $(31,84 \%)$ e D $(30,36 \%)$. Estes valores estão de acordo com os relatados por outros estudos (BARROS et al., 2011; JUSTUS et al., 2011; RIBEIRO et al., 2012). O teor de proteínas de queijos reflete o conteúdo deste componente no leite e varia em função de fatores genéticos, fisiológicos e ambientais, como raça, individualidade do animal, estágio de lactação, idade, alimentação, intervalo entre ordenhas, clima, estação do ano, entre outros (FOX, 2003). Viotto, Cunha (2006) relatam que essas diferenças não podem ser controladas pelo fabricante de queijos, explicando em parte a variabilidade no teor de proteínas encontrada entre diferentes marcas.

O teor de carboidrato variou entre $1,07 \%$ a $15,8 \%$ entre as amostras analisadas. Não foram encontrados teores de carboidratos nas amostras B e E. As amostras A e C apresentaram $1,07 \%$ e $1,81 \%$. Essas baixas concentrações podem ser lactose residual, a qual estava presente no leite e não foi utilizada totalmente pelos microrganismos da cultura lática durante a fabricação dessas marcas de queijo e ficaram retidas na massa durante a dessoragem.

$\mathrm{Na}$ amostra $\mathrm{D}$, com maior concentração $(15,8 \%)$, possivelmente deve ter havido adição de alguma outra substância não amilácea e não proteica, por ter apresentado teste negativo para o lugol e o teor de proteínas esteve dentro dos níveis normais para o produto. Tal substância pode ser uma goma ou uma fibra. Porém, para determinar o que foi adicionado, mais testes são necessários e que não foram realizados neste trabalho.

As pesquisas com queijos ralados encontradas na literatura foram realizadas, principalmente, nos Estados de Minas Gerais (PIMENTEL et al., 2002, JUSTUS et al., 2011; OLIVEIRA et al., 2012) e Rio de Janeiro (ROMANO et al., 2005; DUARTE et al., 2006; TROMBETE et al., 2012), grandes consumidores de queijo do País, com alta rotatividade dos produtos no mercado. Apenas um trabalho realizado no Paraná sobre este tema foi encontrado (RIBEIRO et al., 2012), portanto, há necessidade de monitoramento sistêmico da qualidade dos produtos disponíveis no mercado, o que torna o presente estudo interessante.

\section{CONCLUSÕES}

A composição química (umidade, cinzas, carboidratos, proteínas e lipídios) de queijo parmesão ralado difere de uma marca para outra, devido às diferentes matériasprimas utilizadas e às condições de processamento. Todas as amostras avaliadas estão em conformidade com a legislação brasileira vigente para os teores de umidade, no entanto, $60 \%$ apresentaram valores maiores de gordura no extrato seco do que o permitido. 
Conclui-se que $60 \%$ dos queijos ralados comercializados na cidade de Paranavaí apresentam desconformidade com a legislação brasileira no que tange o conteúdo de GES. Um dos queijos possivelmente foi fraudado por uma substância não amilácea e não proteica, a qual não foi identificada no presente estudo. A legislação brasileira apresenta apenas dois parâmetros para controle de qualidade de queijos ralados, teor de gordura no extrato seco e umidade, dificultando ações de fiscalização e controle por parte dos órgãos responsáveis.

\section{REFERÊNCIAS}

BARROS, J. J. C et al. Queijo Parmesão: caracterização físico-química, microbiológica e microestrutura. Ciência e Tecnologia de Alimentos, v. 31, n. 2, p. 285-294, 2011.

BRASIL. Ministério da Agricultura, Pecuária e Abastecimento. Portaria $n^{\circ} 146$, de 07 de março de 1996. Aprova os Regulamentos Técnicos de Identidade e Qualidade de Produtos Lácteos. Diário Oficial da República Federativa do Brasil, Brasília, 11 mar. 1996.

BRASIL. Ministério da Agricultura, Pecuária e Abastecimento. Portaria $n^{\circ} 353$, de 04 de Setembro de 1997. Aprova o Regulamento Técnico para Fixação de Identidade e Qualidade do Queijo Parmesão, Parmesano, Sbrinz, Reggiano e Reggianito. Diário Oficial da República Federativa do Brasil, Brasília, 08 set. 1997 a.

BRASIL. Ministério da Agricultura, Pecuária e Abastecimento. Portaria $n^{\circ} 357$, de 04 de Setembro de 1997. Aprova o Regulamento Técnico para Fixação de Identidade e Qualidade de Queijo Ralado. Diário Oficial da República Federativa do Brasil. Brasília, 08 set. 1997 b.
CARROLL, S. M. Milk composition of Holstein, Jersey, and Brown Swiss cows in response to increasing levels of dietary fat. Animal Feed Science and Technology, v. 131, n. 3, p. 451-473, 2006.

DUARTE, A. M. et al. Incidência de amido em queijo parmesão ralado. Revista do Instituto de Laticínios Cândido Tostes, n. 353, v. 61, p.16-18, 2006.

FOX, P. F. The major constituents of milk. In: SMITH, G (Ed.). Dairy Processing: Improving quality. CRC Press: Boca Raton, Boston, 2003. Cap. 2.

INSTITUTO ADOLFO LUTZ. Métodos físico-químicos para análise de alimentos, $4^{\mathrm{a}}$ ed., $1^{\mathrm{a}}$ ed. Digital. São Paulo: Instituto Adolfo Lutz, 2008.

INMETRO. INSTITUTO NACIONAL DE METROLOGIA, QUALIDADE E TECNOLOGIA. Produtos analisados: queijo ralado. Disponível em: <http://www. inmetro. gov.br/consumidor/produtos/queijoRalado. asp>. Acesso em: 15 mar. 2003.

JUSTUS, A. et al. Caracterização física e química de queijo parmesão ralado comercializados na região sul de Minas Gerais. Revista do Instituto de Laticínios Cândido Tostes, n. 379, v. 66, p. 6-24, 2011.

OLIVEIRA, L. M. et al. Avaliação da qualidade de queijos ralados para proteção à saúde pública. Revista do Instituto de Laticínios Cândido Tostes, n. 384, v. 67, p. 41-47, 2012.

PEREIRA, D. B. et al. Físico química do leite e derivados: métodos analíticos. $2^{\mathrm{a}}$ ed. Juiz de Fora: Epamig, 2001. 234 p.

PERRY, K. S. Queijos: Aspectos químicos, 
bioquímicos e microbiológicos. Quimica Nova, São Paulo, v. 27, n. 2, 2004.

PIMENTEL, E. F. et al. Avaliação da rotulagem e da qualidade físico-química e microbiológica de queijo ralado. Ciência e Tecnologia de Alimentos, v. 22, n. 3, p. 289-294, 2002.

RIBEIRO, J. C. B., et al. Qualidade físicoquímica e microbiológica do queijo parmesão ralado comercializado em Ponta Grossa. Revista do Instituto de Laticínios Cândido Tostes, n 387, v. 67, p. 21-29, 2012.

ROMAnO, V. P.; AZEVEDo, M. G. A. Pesquisa de Amido em Queijos Parmesão ralados inspecionados e comercializados no município do Rio de Janeiro. CONGRESSO LATINO AMERICANO DE HIGIENISTAS DE ALIMENTOS, 2.;
CONGRESSO BRASILEIRO DE HIGIENISTAS DE ALIMENTOS, 8.; ENCONTRO NACIONAL DE CENTROS DE CONTROLE DE ZOONOSES, 1., 2005. Anais... Búzios: Colégio Brasileiro de Médicos Veterinários Higienistas de Alimentos, 2005, v. 9, n. 130.

TROMBETE, F. M.; FRAGA, M. E.; SALDANHA, T. Avaliação da qualidade química e microbiológica de queijo parmesão ralado comercializado no Rio de Janeiro. Revista do Instituto de Laticínios Cândido Tostes, n. 385, v. 67, p. 11-16, 2012.

VIOTTO, W. H.; CUNHA, C. R. Teor de sólidos do leite e rendimento industrial. In: MESQUITA, A. J.; DURR, J. W.; COELHO, K. O. Perspectivas e avanços da qualidade do leite no Brasil. Goiânia: Talento, 2006. p. 241-258. 